\title{
Modification of Disc Brakes Using Rotating Brake Pads
}

\author{
Bhuvnesh Joshi \\ (Mechanical Engineering, Indore Institute of Science and Technology, India)
}

\begin{abstract}
Under the topic 'Modification of Disc Brakes using Rotating Friction Pads', I have studied different components of disc brake which includes rotor, calipers, and fixed friction pads. My main aim is to increase the braking effect by modifying the existing design by using rotating friction pad. This friction pad is made to rotate in opposite direction as that of rotor, this is done by using a separate assembly of compound gear train. In this assembly 2 shafts are used, one shaft is connected between tire and gear and second shaft connects gear and rotating friction pad. Both the gears are meshed with each other. As the wheel rotates in clockwise direction, the gear attached to it will also rotate. Other gear which is in meshed position with first gear will rotate in anticlockwise direction. This will help to move friction pad in anti-clockwise direction as that of wheel's clockwise motion. Aim for using rotating friction pad is to provide maximum possible friction which results in retardation of motion, rotating friction pad not only will provide the friction due to contact but will also provide the friction due to rotation. Calculations regarding speed of gears, and motion of wheel will clearly elaborate the idea, this slight modification helps in reducing braking time. Important thing in this innovation is that the energy required to stop the wheel or disc of brakes is transmitted from wheel only.

Keywords - Fixed friction pads, increase braking effect, compound gear train, rotating friction pad, reducing braking time.
\end{abstract}

\section{Introduction}

Braking is the process due to which the motion of any machine can either be retarded or brought it to rest. Braking can be done using a component assembly called brakes. A brake is mechanical device which inhibits motion. It is a device for slowing or stopping the motion of a machine or vehicle, or alternatively a device to restrain it from starting to move again. Many inventions have been done and many are under development to accelerate the braking and decelerate the braking time. Right from lever brakes, rope brakes, drum brakes to today's disc brakes, series of evolution have been done.Brakes are broadly classified into-

a. Friction Brakes

b. Regenerative Brakes

c. Hydraulic Brakes

d. Electromagnetic Brakes

Disc brakes come under the category of friction brakes due to their method of actuation. They convert kinetic energy of moving part into heat energy by friction which is then gradually dissipated in the surrounding air. A brake disc (or rotor), usually made of cast iron or ceramic composites (including carbon, Kevlar and silica), is connected to the wheel. To stop the wheel, friction material in the form of brake pads (mounted on a device called a brake caliper) is forced

mechanically, hydraulically, pneumatically or electromagnetically against both sides of the disc. Friction causes the disc and attached wheel to slow or stop.

2.1 Components of Disc Brake Assembly

\section{Theory}

A disc brake assembly comprises of many components but mainly following three components-

a. Disc (disc rotor) that rotates with the wheel

b. Brake Caliper assembly attached to the steering knuckle.

c. Friction materials (disc pads) that are mounted to the caliper assembly.

The disc rotor is made of grey cast iron, and is either solid or ventilated. The ventilated type disc rotor consists of wider disc with cooling fins cast to the middle to ensure good cooling. Proper cooling prevents fading and ensures longer pad life.

Brake calliper's first functional responsibility is to translate the hydraulic fluid pressure from the pipes and hoses into a linear mechanical force. 
The brake pads or friction pads are designed for high friction with brake pad material embedded in the disc in the process of bedding while wearing evenly. Although it is commonly thought that the pad material contactsthe metal of the disc to stop the car, the pads work with a very thin layer of their own material and generate a semi-liquid friction boundary that creates the actual braking force.

\subsection{Basic Working}

Two brake/friction pads are used and are mounted on both sides of the rotor. When brake pedal is pressed, oil starts to flow from master cylinder through hoses and pipes to move piston. This piston presses the friction pads (which are having to and fro motion) towards the rotor which is moving with high speed, friction is produced between friction pads and rotor to retard its motion. Braking is achieved due to friction pads which are providing to and fro motion, this motion provides frictional energy to retard the motion of rotor. Now, a try is being made to enhance the braking effect by slightly changing the design of disc brakes.

\subsection{Proposed Work}

Purpose of using rotating friction pad is that it not only will provide the friction due to contact but will also provide the friction due to rotation. For this a separate assembly of gears is used. Compound gear train assembly is used which will rotate the friction pad which is on outer side of the rotor while the other side of the rotor's pad will only move in to and fro direction. The outer friction pad will be able to move in to and fro as well as in rotational direction. This will take place in following way, let us assume a disc brake is attached to the rotor disc which is further attached to wheel of the vehicle, as soon as vehicle starts to move, wheel and rotor will also move (say clockwise direction). Now one shaft $S_{1}$ is connected to rotor, due to motion of rotor disc shaft will also rotate in clockwise direction. This shaft is connecting the rotor and gear $\mathrm{G}_{1}$, complete motion of wheel and rotor will be transferred to gear $\mathrm{G}_{1}$ and it will also have clockwise motion.

This gear $G_{1}$ is meshed with gear $G_{2}$ in compound gear assembly, velocity ratio can be maintained as per the requirement; as $G_{1}$ rotates in clockwise direction, $G_{2}$ will move in anti-clockwise direction. Again the secondary shaft $S_{2}$ is connected to join $G_{2}$ and the friction pad or brake pad $P_{2}$. Ultimately rotor is moving in clockwise direction and brake pad is moving in anti-clockwise direction, and as the brakes are applied this pad will be pressed to the rotor resulting into friction due to both direct contact and due to retardation in motion.

This can be understood with a simple example, in winter days we rub our palms to feel the warmth generated by rubbing. When we rub only one hand over other the heat generated is low as compared to that when both the hands are rubbed against each other, it produces more heat due to friction. Conclusion is that, when both the hands are rubbed with some speed and specific direction more heat will get generated. Both hands are considered as brake pads and friction produced between hands is the friction produced between rotor and pads due to direct contact.

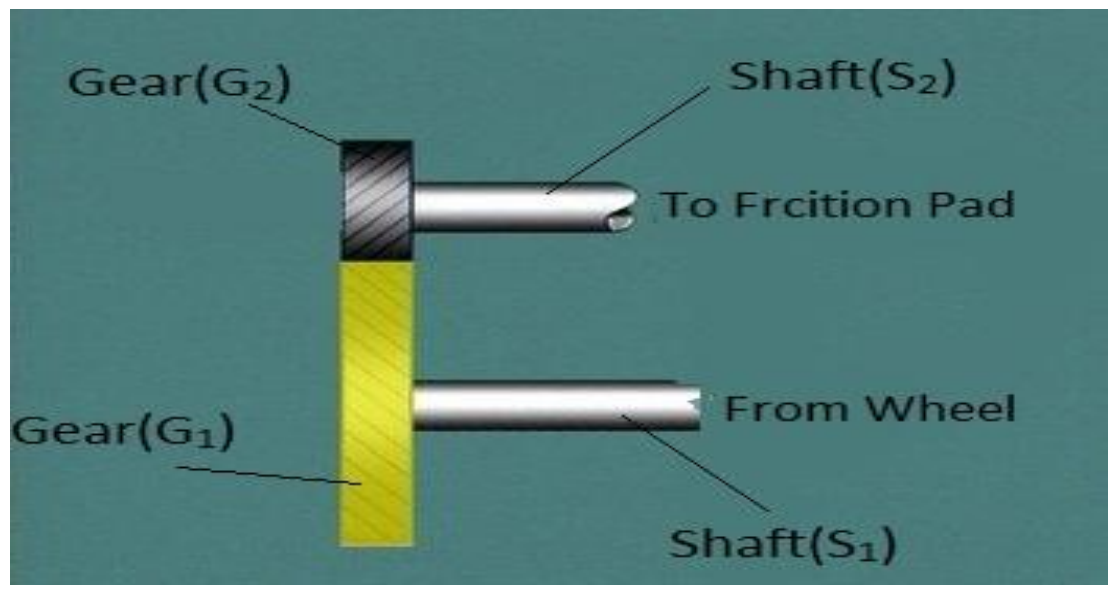

Figure

\subsection{Assumptions}

III. Calculations

Let us assume a wheel of vehicle isin motion andis having disc brake assembly as per shown in Fig.mounted on it.

a) $\quad \mathrm{V}=$ Velocity of wheels $=60 \mathrm{~m} / \mathrm{s}=3600 \mathrm{~m} / \mathrm{min}$

b) $\quad \mathrm{r}=$ Radius of wheel $=0.33 \mathrm{~m}$

c) $\quad r_{1}=$ Radius of $1^{\text {st }} \operatorname{Gear}\left(G_{1}\right)=0.10 \mathrm{~m}$ 
d) $\quad \mathrm{r}_{2}=$ Radius of $2^{\text {nd }} \operatorname{Gear}\left(\mathrm{G}_{2}\right)=0.13 \mathrm{~m}$

e) Centre distance between 2 shafts $=0.13+0.10=0.23 \mathrm{~m}$

f) $T_{1}=$ Number of teeth on $G_{1}=32 \& T_{2}=$ Number of teeth on $G_{2}=42$

g) Power transmission through shafts and gears is assumed to be $100 \%$.

h) $\quad \mathrm{S}_{1}=1^{\text {st }}$ Shaft $\& \mathrm{~S}_{2}=2^{\text {nd }}$ Shaft

i) $\mathrm{m}=$ Module of gear, $\mathrm{m}_{1}=$ module of $1^{\text {st }}$ gear $\& \mathrm{~m}_{2}=$ module of $2^{\text {nd }}$ gear

\subsection{Mathematical Equations}

Circular motion of the wheel can be changed in linear motion by

$2 \pi \mathrm{rN}_{1}=3600$

$2.073 \mathrm{~N}_{1}=3600$

$» \quad \mathrm{~N}_{1}=1736.61 \approx 1737 \mathrm{rpm}$

As power transmission is $100 \%$, so

Speed of wheel $=$ speed of Shaft $S_{1}=$ Speed of Gear $G_{1}$

$\mathrm{N}_{1}=$ Speed of Gear $\mathrm{G}_{1}=1737 \mathrm{rpm}$

Now,

Standard numbers of teeth on gear are 18, 32, 42

So we take,

$\mathrm{T}_{1}=32$

$\mathrm{r}_{1}=\mathrm{m}_{1} \mathrm{~T}_{1} / 2$

$0.10=\mathrm{m}_{1} * 32 / 2$

$\mathrm{m}_{1}=0.00625 \mathrm{~m}=6.25 \mathrm{~mm}$

As, $\quad \mathrm{m}_{1}=\mathrm{m}_{2}=6.25 \mathrm{~mm}$

$\mathrm{r}_{2}=\mathrm{m}_{2} \mathrm{~T}_{2} / 2$

» $\mathrm{T}_{2}=41.6 \approx 42$

So, $\quad \mathrm{N}_{1} \mathrm{~T}_{1}=\mathrm{N}_{2} \mathrm{~T}_{2}$

$1737 * 32=42 \mathrm{~N}_{2}$

$» \mathrm{~N}_{2}=1323.42 \approx 1323 \mathrm{rpm}$

This is the speed of $2^{\text {nd }}$ gear, $\mathrm{G}_{2}$ calculated to be $1323 \mathrm{rpm}$.

Now as power transmission is completely efficient so, the complete rotation will be transferred to brake pad through shaft $S_{2}$. This brake pad which is free to rotate will have the same speed of $1323 \mathrm{rpm}$.

\section{Conclusion}

As the complete work is aimed to increase the braking effect and reduce the braking time, a simple compound gear assembly is used to do so. Braking which occurs due to friction when two surfaces are in close contact is the basic principle which is been used, from the above discussion it is seen that here braking is taking place not only due to close contact of two surfaces but also due to retardation force which is been exerted by the friction pad on the rotor. This results in instant braking with reduced braking time. Speed of wheel/rotor is 1737 $\mathrm{rpm}$ while that of friction/brake pad is $1323 \mathrm{rpm}$ so pads can easily retard the motion on rotor and to achieve greater speed of brake pad gear teeth ratio can be altered.

4.1 Advantages

a) No extra work/power is required to enhance the braking effect as pad is extracting the power to rotate from rotation of wheel only.

b) Braking time is reduced and braking effect is increased.

c) It assures ease of operation.

4.2 Applications

a) This type of brake assembly can be used in almost every vehicle where disc brakes are used to enhance braking effect.

b) In vehicles, especially four wheeler this assembly can be installed to achieve braking in very less time and with increased braking efficiency.

c) Sports cars where instant braking is a necessity can use this technique.

\section{References}

Books:

[1] R.S.Khurmi, Machine Design (Published by S.Chand, New Delhi, 2009).

Chapters in Book:

[2] Brakes, R. S. Khurmi, Machine Design, (S.Chand Publications, New Delhi, 2009).

[3] Gears, R. S. Khurmi, Machine Design, (S.Chand Publications, New Delhi, 2009). 